\title{
Ultrasound tissue characterization - to measure matrix integrity and to quantify regenerative processes in equine tendons and ligaments
}

\section{Caracterización tisular ultrasonográfica - para medir integridad de la matriz y cuantificar los procesos regenerativos en tendones y ligamentos equinos}

\author{
Hans van Schie ${ }^{1}$ \\ ${ }^{1}$ UTC Imaging, The Netherlands. Email: hans.vanschie@utcimaging.com
}

\begin{abstract}
Tendon injuries often threaten the athletic career of performance horses. There may be single overloading but frequently the injury is the result of a gradual matrix degradation, initially without clinical signs, which may lead to impaired regenerative capacity. Another complicating factor is the lack of uniform pathology; frequently multiple stages of matrix integrity can be found and, therefore, there is no cureall treatment. Ultrasound Tissue Characterization (UTC) is designed for tomographic visualization and quantification of 3-D matrix integrity. UTC is based on standardized compilation of ultrasounddata by means of an ultrasound probe that moves automatically along the tendon's long axis, collecting transverse images every $0.2 \mathrm{~mm}$, generating a 3-D volume. UTC-algorithms can discriminate 4 different echo-types, related to size and integrity of structures in the matrix (van Schie et al. 2003):
\end{abstract}

- Echo-type I, generated by intact and aligned fascicles with axial diameter $\geq$ spatial resolution.

- Echo-type II, generated by discontinuous, waving and/or swollen fascicles with axial diameter $\geq$ spatial resolution.

- Echo-type III, generated by a matrix mainly consisting of fibrils with axial diameter $<$ spatial resolution.

- Echo-type IV, generated by a mainly amorphous matrix and fluid.

Fundamental research with isolated tendons revealed that the ratios of these 4 echo-types are highly correlated with tendon matrix integrity, showing the discriminative power of UTC for tissue characterization (van Schie et al. 2009).

Normal superficial digital flexor tendons in young mature horses are characterized by $80-90 \%$ type I, $10-15 \%$ type II and barely any type III and/or IV echoes. Loss of integrity is characterized by significant changes like decrease of type I, increase of type II (remodeling or inferior repair) and increase of type III (fibrillar) and/or IV (amorphous). Intra- and inter- observer reliability appeared to have intra-class correlations (ICC) ranging 0.92-0.98, indicative for excellent reproducibility. Clinical research revealed that UTC is sensitive and reliable to: • Monitor load-effects and detect matrix degradation (Plevin et 
Ciencias

Veterinarias
Rev. Ciencias Veterinarias, Vol. 37, N 3, [32-33], E-ISSN: 2215-4507

First Symposium on Regenerative Medicine and Nanotechnology, Costa Rica 2019 DOI: https://doi.org/10.15359/rcv.37-3.12

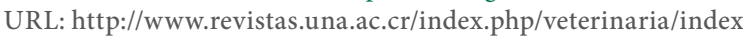

al. 2019). Stage lesions for selection of appropriate intervention. • Quantify regenerative processes for objective evaluation of therapy and guided rehabilitation (Bosch et al. 2011).

\section{References}

Bosch, G., van Weeren, P.R., Barneveld, A. \& van Schie, H.T. 2011. Computerized analysis of standardized ultrasonographic images to monitor the repair of surgically created lesions in equine superficial digital flexor tendons following treatment with intratendinous platelet rich plasma or placebo. Vet. J. 187(1): 92-98. DOI: 10.1016/j.tvjl.2009.10.014

Plevin, S., McLellan, J., van Schie, H.T. \& Parkin, T. 2019. Ultrasound tissue characterization of the superficial digital flexor tendons in juvenile Thoroughbred racehorses during early race training. Equine Vet. J. 51(3): 349-355. DOI: 10.1111/evj.13006

Van Schie, H.T., Bakker, E.M., Jonker, A.M. \& van Weeren, P.R. 2003. Computerized ultrasonographic tissue characterization of equine superficial digital flexor tendons by means of stability quantification of echopatterns in contiguous transverse ultrasonographic images. Am. J. Vet. Res. 64(3): 366-375.

Van Schie, H.T., Bakker, E.M., Cherdchutham, W., Jonker, A.M., van de Lest, C.H. \& van Weeren, P.R. 2009. Monitoring of the repair process of surgically created lesions in equine superficial digital flexor tendons by use of computerized ultrasonography. Am. J. Vet. Res. 70(1): 37-48. DOI: 10.2460/ajvr.70.1.37 